Portland State University

PDXScholar

\title{
Associations between Willingness to Exert Cognitive Effort and Smoking Abstinence
}

\author{
Austin A. Phanouvong \\ Portland State University \\ Darby K. Dyar \\ Oregon Health \& Science University \\ Suzanne H. Mitchell \\ Oregon Health \& Science University
}

Follow this and additional works at: https://pdxscholar.library.pdx.edu/honorstheses

\section{Let us know how access to this document benefits you.}

\section{Recommended Citation}

Phanouvong, Austin A.; Dyar, Darby K.; and Mitchell, Suzanne H., "Associations between Willingness to Exert Cognitive Effort and Smoking Abstinence" (2017). University Honors Theses. Paper 444.

https://doi.org/10.15760/honors.441

This Thesis is brought to you for free and open access. It has been accepted for inclusion in University Honors Theses by an authorized administrator of PDXScholar. Please contact us if we can make this document more accessible: pdxscholar@pdx.edu. 


\title{
Associations between Willingness to Exert Cognitive Effort and Smoking Abstinence
}

\author{
Austin A. Phanouvong ${ }^{4}$, Darby K. Dyar ${ }^{1}$, Suzanne H. Mitchell ${ }^{1,2,3}$ \\ ${ }^{1}$ Behavioral Neuroscience; ${ }^{2}$ Psychiatry; ${ }^{3}$ Oregon Institute of Occupational Health Science; \\ Oregon Health \& Science Univ., ${ }^{4}$ Portland State Univ., Portland OR, USA
}

\begin{abstract}
:
In decision-making tasks, individuals who prefer smaller, immediate rewards over larger, delayed rewards (delay discounting) are less likely to quit smoking. Indeed, decision-making tasks with delayed reward costs are sensitive to many aspects of substance use disorders. However, other reward costs might also be important. Our study focused on one of these other reward costs, which was cognitive effort (CE). 22 current smokers who were anticipating quitting in the near future were recruited to validate if more CE discounting predicted shorter abstinence times in reinforced smoking lapse period. Each participant had to be aged 18-45, and smoke 10-20 cigarettes daily. It was suspected that participants with larger values of the areas under the curve (AUC) of the CE discounting task would have shorter abstinence times. The results show that there was no correlation between performance on the CE discounting task and abstinence times of the lapse periods. The area under the curve values for delay discounting showed no correlation to smoking lapse times just as the CE discounting. This reinforces the suggestion for improvements needed for the lapse period and not the discounting tasks.
\end{abstract}




\section{Introduction:}

In decision-making tasks, many individuals with substance use disorders (SUDs) have a higher preference of smaller immediate rewards over the larger, delayed ones ("delay discounting"; recent reviews: e.g.(Madden and Johnson 2010, Bickel, Jarmolowicz et al. 2012). These delay discounting biases have been strongly correlated with the development and cessation of substance use disorders in individuals as well. But there has been little research on other decision-making tasks with the reward costs being other than a delay period.

Cognitive effort is one potential reward cost that may have a closer relationship to the psychopathology of individuals than delay tolerance. Cognitive effort can be defined as the amount of executive function that must be engaged for a rewardable outcome, such as paying attention in a class to do well and remembering certain things for later. Perhaps, the more or less willing individuals are to exert effort can be related to different types of behaviors and disorders that may affect the treatment/cessation process of individuals that struggle with substance use (Salamone, Yohn et al. 2016). A heightened willingness could predict more participation and engagement of rehabilitation programs or for those adopting healthier behaviors, such as a diet. A lowered willingness to exert effort may be related to characteristics of apathy, anhedonia, and depressions, which could affect the engagement and fulfillment of treatment programs for SUDs.

We aimed to explore the predictive validity of cognitive effort discounting in smokers who were contemplating about quitting. By correlating their discounting biases with their ability to abstain from smoking in a modified smoking lapse period (McKee, Weinberger et al. 2012), we predicted that the less willing the participants are, the faster they will lapse in that period. 


\section{Methods:}

\section{Participants}

Participants were recruited through fliers around college campuses, cafes, and bars. Craigslist was also a platform for recruiting participants. The interested participants were initially screened through telephone and email, then invited for a more in-depth face-to-face screening if they passed. Inclusion criteria for the telephone/email screening was: the participants had to be $18-45$ years old, smoke 10 to 20 cigarettes daily, had a high school diploma or equivalent, were fluent in reading and writing English, and contemplated quitting smoking within the next 6 months. In the face-to-face screening, participants completed a health questionnaire including medical and drug use history, have a breath carbon monoxide (BCO) level of 8ppm or greater, blood alcohol levels (BAL) lower 0.03 using an alcohol breathalyzer, and passed a drug and pregnancy urine test. Individuals were excluded if they had (1) a history of substance use disorder except nicotine dependence (DSM-IV criteria: American Psychiatric Association, 2000), (2) current physical or psychiatric problems, and (3) a history of serious psychiatric disorder (DSM-IV, Axis 1 disorders).

\section{Procedure}

Table 1 shows the activities that occurred during the experimental session. At the start the participant were given an opportunity to smoke. If they hadn't smoked within two or three hours, we would encourage them to smoke to keep consistency throughout participants. The participants then began by the session by repeating eligibility measures such as the drug and pregnancy tests, BCO and BAL tests, and collecting saliva samples for further carbon monoxide analysis. After the tests, the participants practiced the cognitive effort task and answered multiple questionnaires in regard to smoking urges and withdrawal, personality, and cognition. The smoking urges and withdrawal questionnaire were completed multiple times throughout the study. Participants then moved into the tasks. First, they completed the original delay discounting task featured in Mitchell 1999, and then began the attentional cognitive effort task and its associated discounting questions. Participants completed the smoking urges and 
withdrawal, then began the two-hour smoking lapse period and self-administration period. After that they were assessed for smoking urges and withdrawal again, and completed more cognitive effort tasks and discounting questions.

This lapse procedure involved a 120 minute period in which 8 cigarettes of the participants' preferred brand were placed next to the television, in their line of sight. The participants were instructed that for every 5 minutes they abstain from smoking, they would earn $\$ 0.15$. The original lapse procedure had a monetary reinforcement of $\$ 0.25$ for every 5 minutes in a 50 minute period. We have extended the lapse period to 2 hours and lowered the monetary reward to increase the likelihood of participants to smoke within the lapse period. The participants were enclosed in a ventilated room for the whole two hours regardless if they smoked or not. A live streaming camera was placed in the room and focused on the cigarettes and an elapsing timer. During this period, participants were allowed to watch a movie or read a book or magazine.

The self-administration period followed right after the smoking lapse period. This was a 60 minute period where the participant could smoke however many cigarettes they wanted without penalty. The purpose for this period was to assess the self-control of the participants. Since the cigarettes are free and there is no penalty for smoking, the self-control of the participants can be measured by how much they smoke within that hour. Also, this period was used root out suspicious participants. For example, if a participant abstained for the whole smoking lapse period and the self-administration period, then it questions their legitimacy to being a smoker. After the participants were done with the self-administration period, they are reassessed for smoking urges and withdrawal.

\section{Dependent Measures}

\section{Questionnaires}

The participants answered questionnaires to assess their mental processes of urges, withdrawal, and different types of cognition and engagement. The smoking urges were measured with the Brief Questionnaire of Smoking Urges (QSU) (Cox, Tiffany et al. 2001) and 
the withdrawal was measured with the Minnesota Nicotine Withdraw Scale (MNWS) (Hughes and Hatsukami 1986). The QSU and MNWS were answered throughout the experimental session to compare differences in participants' urges and withdrawal as they completed different parts of the experiment. There were six different questionnaires that assessed the different types of cognition and engagement. These scales and measures gave a better understanding of the participants' willingness to engage in cognitive effort prior to the discounting task. Apathy, which is the lack of motivation or interest, was one of the measures. It was assessed using the Apathy Evaluation Scale (Marin, Biedrzycki et al. 1991, Clarke, Ko et al. 2011), which had the participants evaluate their general engagement in different activities and situations. Association with self to different types of cognition characteristics was measured with the Brief Need for Cognition Scale (Cacioppo and Petty 1982). The Distress Tolerance Scale (Simons and Gaher 2005) was used to measure the state of distress in certain situation, and the Grit Scale (Duckworth, Peterson et al. 2007) measured their perseverance and passion of a long term goal (grit). Persistence and procrastination of the individuals were also assessed using the Persistence Preservation Perfectionism Scale (Serpell, Waller et al. 2009) and Pure Procrastination Scale (Steel 2010) respectively.

\section{Delay Discounting Task}

Because the Cognitive Effort Discounting Task was derived from the Delay Discounting Task, the participants did a task based on the task developed by (Mitchell 1999) for comparison. The task involved participants going through a series of choices between a small immediate reward and a larger later reward. To stay consistent, the reward amounts matched the cognitive effort rewards amounts.

\section{Attentional Task}

The cognitive effort task that the participants had to perform was an attentional based task. The cognitive effort task was one minute long and done on the computer. For every one second, one of the four stimuli (arrow direction) would appear at a random location on the 
screen. The participant then had the following second to respond with the correct arrow key. This process was repeated until one minute had passed. At the end, the task generated a feedback percentage on how well the participants did.

\section{Attentional Cognitive Effort Discounting Task}

The discounting task consisted of 48 questions asking participants whether they prefer a small monetary reward for exerting no effort (range \$0-\$26) or a larger reward (\$25) for exerting the effort to complete attentional task (described above) for a specific duration (1, 5, 10, 20 mins). The small reward amount varied within the monetary range, while the larger reward was fixed. But the task duration for the large reward choice changed with every question. Participants kept in mind that when choosing the larger reward, they would be expected to perform the task with a correct response rate of $80 \%$ or greater to receive the reward. For example, if they choose a larger reward for doing 10 minutes of the attentional task, the participant must be confident enough to get $80 \%$ or higher correct in the task when choosing this preference. This was enforced using the "potentially-real reward" protocol, where one of discounting question was chosen at random, and the participant would receive money for no effort, or have to perform the task at the specific duration level to receive \$25 (accuracy must be $\geq 80 \%$ to obtain the money) depending on what he/she had selected as the preferred alternative on that questions. The indifference point, or the amount of money of the small reward at which the participants changed their preference for the larger more effort requiring reward, was calculated for each task duration. Methods to find these indifference points and produce AUC values were the same as those previously used (e.g., (Mitchell 1999),(Mitchell and Wilson 2012). These indifference points were used to generate the area under the curve (AUC) values, which is a representation of the willingness to exert cognitive effort. 


\section{Results:}

Currently we have completed 22 participants, and will continue the study until we have reached our goal of 72 participants. Table 2 shows the demographics of the current completed participants. The study had about equal amounts of male (12) and female (10). The average age was 31 years old which is about the median of our age eligibility. About three-fourths of the participants currently drank alcohol on a weekly basis and a little over a third used marijuana daily. There was less than $15 \%$ of participants who have used for each lifetime recreational drug type except marijuana. About half of the participants have used marijuana in some form or another. The daily amount of cigarettes averages to be around 10 cigarettes a day, which indicated a heavy smoking population. Nicotine dependence scores are from the Fagerstrom Nicotine Dependence Test (Fagerstrom and Schneider 1989). The average score shown indicates that this study population is not highly dependent on cigarettes. The Contemplation Ladder score indicates that these participants are in the early stages of cessation.

The modified smoking lapse period only had about half the participants lapsing within the two-hours. Figure 1 shows a survival analysis graph of the percentage of the participants that did not lapse and the lapse times. As time increases in the lapse period, the percentage of participants that did not lapse decreases. Approximately $45 \%$ of the participants lapsed before the lapse period came to an end.

The cognitive effort discounting data showed a good discounting curve represented in Figure 2. The graph plots the indifference point (small reward amount where preference is changed) of each task duration. As the task duration increased, the small reward amount where the preferences for exerting cognitive effort for the large amount of money (large more effort requiring reward) decreased. The AUC can be generated from this data plot by utilizing the trapezoidal approximation of the curve. The AUC is a good representation of the willingness to exert cognitive effort because it is related to the amount of times the participant chose the larger more effort requiring reward.

The individual AUCS of the participants were compared to their times they lapsed. Figure 3a shows the cognitive effort discounting AUC, while Figure $3 b$ is comparing with the delay discounting AUC. The cognitive effort did not have any correlation to the lapse times, and 
as well as delay discounting. Each figure shows a slight negative value in the slope, which is not what we would like. 


\section{Discussion and Conclusion:}

Contrary to our expectations, the willingness to exert cognitive effort was not correlated to the smoking lapse time of the participants. The AUC of the participants' cognitive effort discounting data was unrelated to their lapse times. Some participants were more willing to exert cognitive effort, but lapse quickly. And others were not as willing, but lasted for the entire lapse period. But the cognitive effort discounting data does follow the same patterns as delay discounting.

In Krishnan-Sarin et al (2006) article, delay discounting was successfully correlated with the outcomes of a smoking cessation program. AUC values were generated in this study and it showed that participants that did not abstain from the program had lower AUC values (discounted more) than those who abstained throughout the program. With delay discounting having this connection and cognitive effort discounting following the same patterns, it shows that cognitive effort discounting might be indirectly correlated to successful smoking cessation. Also, cognitive effort discounting may bring along a closer and deeper understanding to the psychopathology of substance use individuals than delay.

With the delay discounting AUC values having no correlation to the lapse times as well, it suggests that adjustments have to be made to the smoking lapse period. Both the cognitive effort provides a good representation of the participants' willingness. However according to the survival analysis (Figure 1), approximately $45 \%$ of the participants smoked in the lapse period. This might be due to the lapse period stipulations not being reinforced enough for the participant to start smoking and lapse. And also with delay discounting AUC values not correlating to the lapse times as well, it points toward that improvements are needed for the lapse times.

\section{Limitations}

Some adjustments to the lapse period we can make moving forward is to lower the monetary reinforcement for abstaining from smoking. Also, increasing the delay period for that monetary reinforcement as well. Currently, the participants earn $\$ 0.15$ for every 5 minutes they 
don't smoke. If we decreased the delay time to $\$ 0.10$ and the delay to 10 minutes instead, participants would be more likely to lapse. The stipulations become not worth it for the participants, so they resort to lapsing. Another is to collect any personal items the participants bring with them, such as phones, tablets, books, etc. These items could have distracted participants resulting in no smoking. Also, participants have a choice to watch a movie in the lapse period, and our thoughts is that the majority of our movie selection may be too engaging for the participants. We could correct this by us selecting the movie they watch or offer a less engaging selection.

Other contributing factors could be that the participants could be sleeping through the smoking lapse. Participants are enclosed in a smoking room with cushiony chairs. While this aids in the relaxation of the participant, it might a good opportunity to get a quick nap in. The way the camera is positioned in the room, it is difficult to see the participant. The camera must be focused on the timer and the cigarettes at all times, so there is a blind spot where the participant usually sits. We can correct this by rearranging the room or repositioning the camera. Although there was no correlation between the willingness to exert cognitive effort and smoking lapse times, the study will continue toward its goal of 80 participants. With more participants and corrections made to the lapse time, the resulting data will look a lot different. 


\section{Acknowledgements}

I would like to thank: Dr. Suzanne Mitchell for being the PI on this study and being an incredible

mentor, Darby Dyar for helping out on the study and running participants, Oregon Health and Sciences University and Portland State University, BUILD EXITO for being an amazing research program, and the Portland State University Honors program as well. Here are the grant numbers as well: DA040854, GM118964, 5TL4GM118965-03, 5UL1GM118964-03, 5RL5GM118963-03. 


\section{References}

Bickel, W. K., et al. (2012). "Excessive discounting of delayed reinforcers as a trans-disease process contributing to addiction and other disease-related vulnerabilities: Emerging evidence." Pharmacology and Therapeutics 134(3): 287-297.

Cacioppo, J. T. and R. E. Petty (1982). "The need for cognition." Journal of Personality and Social Psychology 42(1): 116-131.

Clarke, D. E., et al. (2011). "Are the available apathy measures reliable and valid? A review of the psychometric evidence." Journal of Psychosomatic Research 70(1): 73-97.

Cox, L. S., et al. (2001). "Evaluation of the brief questionnaire of smoking urges (QSU-brief) in laboratory and clinical settings." Nicotine \& Tobacco Research 3(1): 7-16.

Duckworth, A. L., et al. (2007). "Grit: perseverance and passion for long-term goals." Journal of Personality and Social Psychology 92(6): 1087-1101.

Fagerstrom, K. O. and N. G. Schneider (1989). "Measuring nicotine dependence: A review of the Fagerstrom Tolerance Questionnaire." Journal of Behavioral Medicine 12(2): 159-182.

Hughes, J. R. and D. Hatsukami (1986). "Signs and symptoms of tobacco withdrawal." Archives of General Psychiatry 43(3): 289-294.

Krishnan-Sarin, S., Reynolds, B., Duhig, A. M., Smith, A., Liss, T., McFetridge, A., ... Potenza, M. N. (2007). Behavioral Impulsivity Predicts Treatment Outcome in a Smoking Cessation Program for Adolescent Smokers. Drug and Alcohol Dependence, 88(1), 79-82.

Madden, G. J. and P. S. Johnson (2010). A delay-discounting primer. Impulsivity: The behavioral and neurological science of discounting G. J. Madden and W. K. Bickel. Washington, DC, American Psychological Association: 213-242.

Marin, R. S., et al. (1991). "Reliability and validity of the Apathy Evaluation Scale." Psychiatry Research 38(2): 143-162. 
Mitchell, S. H. (1999). "Measures of impulsivity in cigarette smokers and non-smokers." Psychopharmacology 146(4): 455-464.

Mitchell, S. H. and V. B. Wilson (2012). "Differences in delay discounting between smokers and nonsmokers remain when both rewards are delayed." Psychopharmacology 219(2): 549-562.

McKee, S. A., et al. (2012). "Developing and validating a human laboratory model to screen medications for smoking cessation." Nicotine \& Tobacco Research 11: 1362-1371.

Salamone, J. D., et al. (2016). "Activational and effort-related aspects of motivation: neural mechanisms and implications for psychopathology." Brain 139(Pt 5): 1325-1347.

Serpell, L., et al. (2009). "The roles of persistence and perseveration in psychopathology." Behavior Therapy 40(3): 260-271.

Simons, J. S. and R. M. Gaher (2005). "The Distress Tolerance Scale: Development and Validation of a Self-Report Measure." Motivation and Emotion 29(2): 83-102.

Steel, P. (2010). "Arousal, avoidant, and decisional procrastinators: Do they exist?" Personality and Individual Differences 48: 926-934. 
Table 1: Event Checklist of the experimental session

\begin{tabular}{|c|c|}
\hline Time (elapsing) & Event \\
\hline Session begins: 0 mins & $\begin{array}{ll}\square & \text { Opportunity to Smoke } \\
\square & \text { BCO and BAL Measurements } \\
\square & \text { Drug and Pregnancy Tests } \\
\square & \text { Collect Saliva sample }\end{array}$ \\
\hline 15 mins & $\begin{array}{l}\text { Practice cognitive effort task } \\
\square \text { Complete questionnaires } \\
\text { - QSU and MNWS } \\
\text { - BNCS } \\
\text { - AES } \\
\text { - DTS } \\
\text { - PPP } \\
\text { - PPS } \\
\text { - Grit }\end{array}$ \\
\hline 60 mins & $\begin{array}{l}\text { Complete delay discounting } \\
\text { task } \\
\text { Complete attentional } \\
\text { cognitive effort task } \\
\square \text { Complete attentional } \\
\text { cognitive effort discounting } \\
\text { task }\end{array}$ \\
\hline $1 \mathrm{hr} .20 \mathrm{mins}$ & $\square \quad$ Complete QSU and MNWS \\
\hline $1 \mathrm{hr} .30 \mathrm{mins}$ & $\begin{array}{ll}\square & \text { Complete smoking lapse } \\
\text { period (120 mins) } \\
\square \\
\text { Complete self-administration } \\
\text { period ( } 60 \text { mins) }\end{array}$ \\
\hline $\begin{array}{l}4 \text { hrs. } 30 \text { mins } \\
\text { Session end: } 5 \text { hrs. }\end{array}$ & $\begin{array}{ll}\square & \text { Complete QSU and MNSW } \\
\square & \text { Complete attentional } \\
\text { cognitive effort task } \\
\square \\
\text { Complete attentional } \\
\text { cognitive effort discounting } \\
\text { task }\end{array}$ \\
\hline
\end{tabular}


Table2: Demographic table of participants

\begin{tabular}{|lc|}
\hline & Participants \\
\hline N (Males:females) & $22(12: 10)$ \\
Age (years) (SD) & $31.55(6.97)$ \\
& \\
Current drug use (Percent who reported use in the last 30 days) \\
Alcohol & $77.27 \%$ \\
Marijuana & $36.36 \%$ \\
& \\
Mean (SD) amounts of current drug use for those who use \\
Alcohol drinks/week & $7.21(11.94)$ \\
Marijuana joints/week & $0.83(7.67)$ \\
& \\
Lifetime recreational drug use (Percent who reported lifetime use) & $4.55 \%$ \\
Stimulants & $4.55 \%$ \\
Sedatives/tranqilizers & $13.64 \%$ \\
Hallucinogens & $9.09 \%$ \\
Opiates & $45.45 \%$ \\
Marijuana & $4.55 \%$ \\
Other (includes inhalants) & \\
& \\
Cigarettes/day (SD) & $9.91(5.62)$ \\
Fagerström score (SD) & $2.86(1.88)$ \\
Contemplation Ladder Score Mean (SD) & $5.45(2.7)$ \\
\hline
\end{tabular}

Figure 1: Survival Analysis of the participant lapse times.

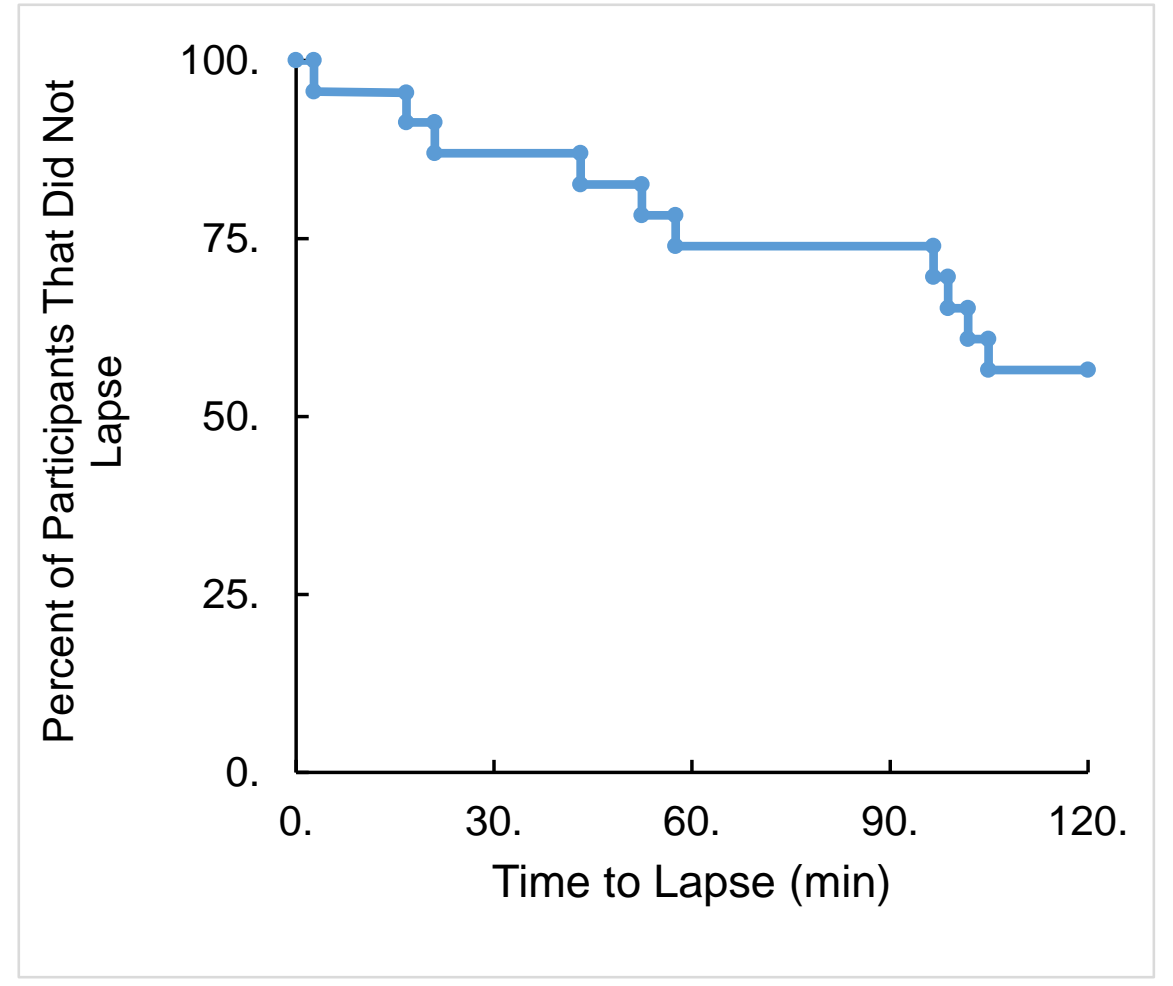


Figure 2: Cognitive effort discounting curve. The indifference points are plotted for the each duration.

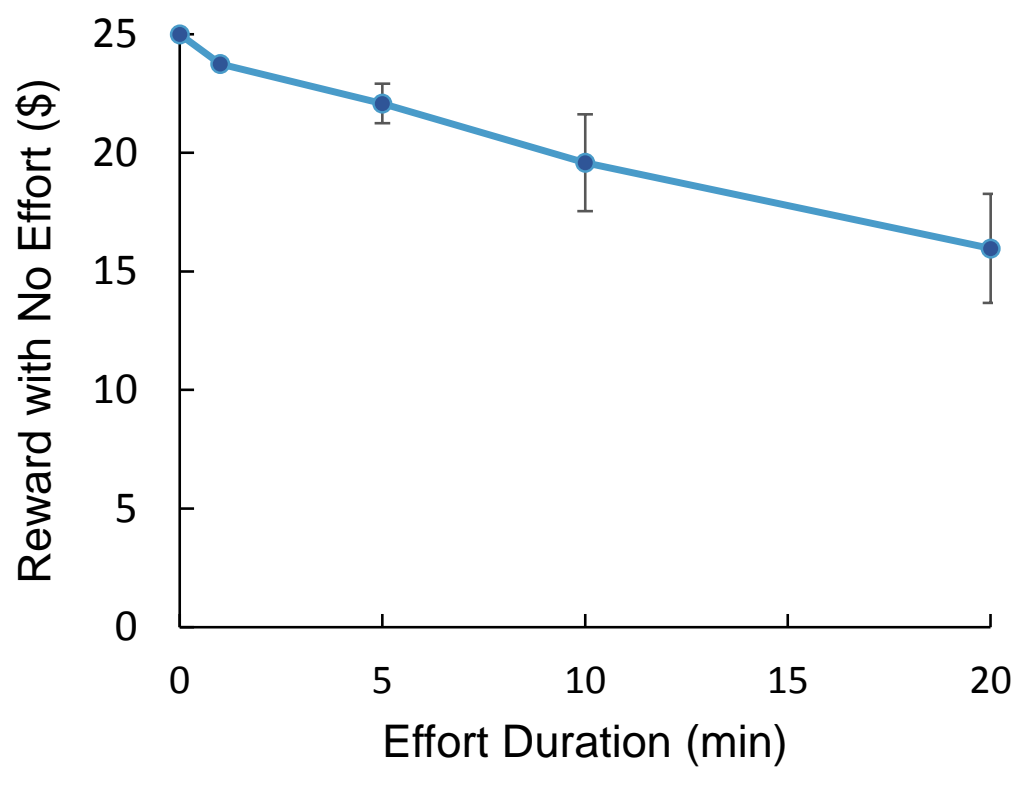

Figure 3: Discounting correlations with the participant lapse times. a) Cognitive effort discounting AUC compared to the lapse times of participants. b) Delay discounting AUC compared to the lapse times of participants.
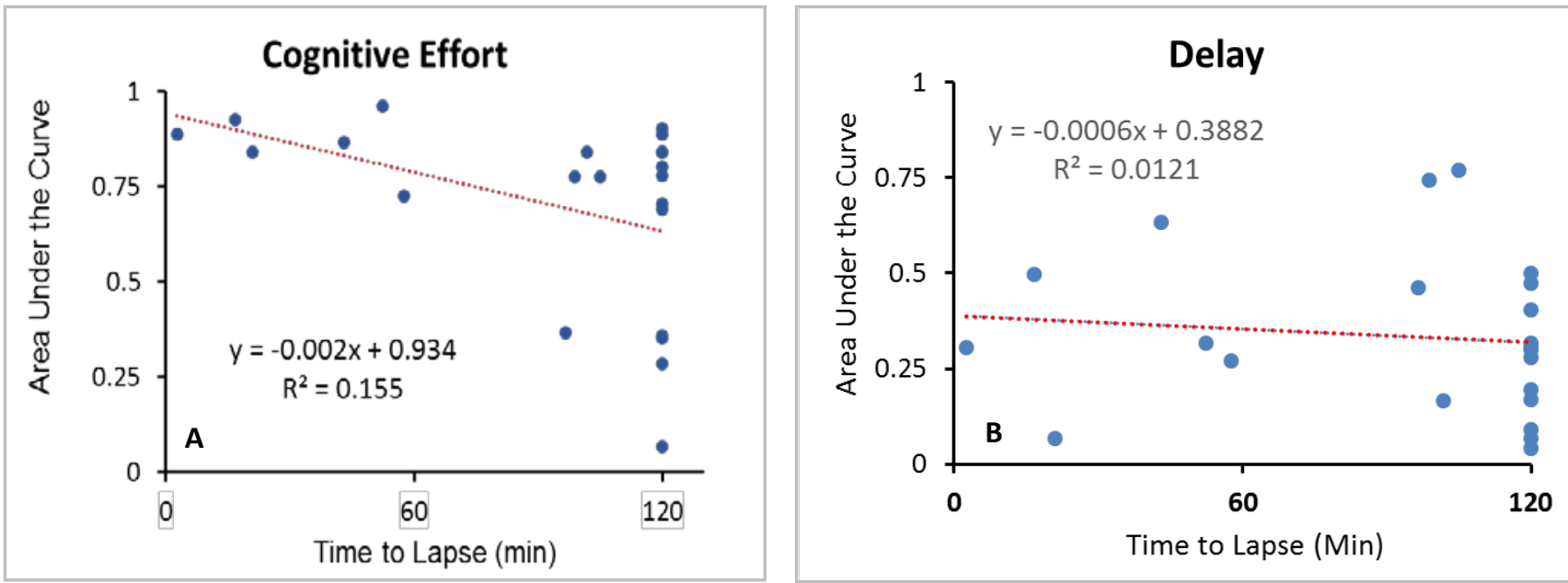